\title{
Pomegranate physiological responses to partial root drying under field conditions
}

\author{
Basile Noitsakis ${ }^{1}$, Antigoni Chouzouri², Lamprini Papa², Angelos Patakas²* \\ ${ }^{1}$ Laboratory of Plant Ecophysiology, Aristotle University of Thessaloniki, Thessaloniki, Greece, ${ }^{2}$ Laboratory of Plant Production, University of \\ Patras, G. Seferi Agrinio, Greece
}

\section{A B S T R A C T}

\begin{abstract}
The results of various levels of Partial Root Drying (PRD) application on pomegranate (Punica granatum L. cv. Wonderful) physiological and fruit quality parameters were studied under field conditions. Three irrigation regimes were applied: control (C) in which plants were watered at both parts of the rootzone to fully compensate evapotranspirational water losses; and partial root drying (PRD1 and PRD2) receiving $100 \%$ and $50 \%$ irrigation water of control plants, respectively. PRD plants exhibited lower values of physiological parameters compared to the control plants. PRD1 maintained higher values of hydrodynamic parameters throughout the experimental period. On the other hand, there were no significant differences in photosynthetic rate (Pn) between PRD1 and control plants. PRD2 plants exhibited significant lower values of all physiological parameters suggesting that the irrigation amount applied could not compensate water losses. Furthermore, higher level of water stress in PRD2 treatment resulted in a significant decrease in mean fruit weight and diameter. No significant effects of different irrigation methodologies on total titratable acidity and juice percentage were evident. Among all treatments, fruit cracking was significantly lower in PRD1 treatment, a fact that was associated with the maintenance of plant water status in this treatment throughout the experimental period.
\end{abstract}

Keywords: Fruit quality; Partial root drying; Punica granatum; Water relations

\section{INTRODUCTION}

Pomegranate has been recognized as an emerging crop in the Mediterranean baisin where its cultivation is continuously increasing mainly due to the favorable organoleptic characteristics of the arils and to the already proven beneficial effects of pomegranate fruits consumption on human health. Pomegranate is also thought to be drought tolerant, a fact that makes it attractive to farmers in areas facing water shortage. Despite the fact that pomegranate is characterised as fairly drought resistant, still requires regular watering in order to maintain high productivity. Many reports concluded that drought stress could have significant negative effects on fruit quality of pomegranate (Mellisho et al., 2012; Mena et al., 2013). As a result, in arid and semi-arid areas increasing of irrigation water efficiency is considered as very important in order to prevent drought stress and maintaine plants productivity (Laribi et al., 2013). In this areas, novel irrigation water saving techniques, such as Partial Root Drying (PRD) have been proposed. PRD refers to the deliberate wetting and drying of alternate sites of the root zone so that the production of specific root-sourced chemical signals will be optimized inducing partial stomatal closure and thereby increasing irrigation use efficiency (Santos et al., 2003; Beis and Patakas 2015). However, till now, the results of PRD implementation in plants performance remained controversy mainly due to differences in soil type (Kriedemann and Goodwin, 2003), variety, environmental and experimental conditions (Rodrigues et al., 2008), methodology in applying PRD irrigation management (Smart et al., 2005; Beis and Patakas 2010) as well as in chemical signaling production and its effects on stomata. To the best of our knowledge, little information exists regarding the effects of PRD on pomegranate plants performance. Furthermore, irregular pomegranate irrigation leading in rapid changes in plant water status have been reported to result in serious physiological disorders with severe economic impact such as the ripe fruits cracking (Prasad et al., 2003; Holland et al., 2009).

\footnotetext{
*Corresponding author:

Angelos Patakas, Laboratory of Plant Production, University of Patras, G. Seferi 2, 30100 Agrinio, Greece.

E-mail: apatakas@upatras.gr; apatakas@cc.uoi.gr
}

Received: 11 February 2016;

Revised: 07 April 2016;

Accepted: 07 April 2016;

Published Online: 27 April 2016 
Thus, the aim of this study is to evaluate the effects of PRD methodology in plant physiological parameters as well as in quality attributes of pomegranate fruits.

\section{MATERIALS AND METHODS}

The experimental pomegranate orchard is located in Northern Greece and consists of 12-years old plants (Punica granatum L. cv. Wonderful). All plants were properly irrigated during the growing season using a drip irrigation system with two irrigation drip lines installed, one at each side, at a distance of $30 \mathrm{~cm}$ from the trunk of the plants. Irrigation water was applied with two emitters $(4 \mathrm{~L} / \mathrm{h})$ per plant, positioned at a distance of $30 \mathrm{~cm}$ from the vine trunk. Microclimatic parameters were continuously recorded to estimate daily reference evapotranspiration (ET) using a agrometeorological station (Delta-T Devices, UK), which was established in the experimental field (Fig. 1).

During the first two months after the bud break the plants were uniformly irrigated to establish $100 \%$ of the estimated crop evapotranspiration. The latter was estimated as a product of reference evapotranspiration (ET) and crop coefficient $(\mathrm{kc})$. ET was calculated using the hourly values of microclimate parameters according to the Penman Monteith formula (Allen et., al 1998). Kc values used, varied from 0,27 early in Spring (April) to 0,77 during the summer period (Intrigliolo et al., 2011; 2013). Thereafter, the experimental orchard was divided in three plots, each one consisting of three rows. The following irrigation regimes were applied: fully-irrigated control plants (C) in which the plants were irrigated at both sides of the root system in order to establish $100 \%$ of the estimated crop evapotranspiration; partial root drying (PRD1) with half of the root system of each plant exposed to soil drying while the other half received $100 \%$ irrigation water of the irrigation water volume applied to control plants; partial root drying (PRD2) with half of the root system of each plant exposed to soil drying while the other half received only $50 \%$ irrigation water of that applied to control plants.

Predawn leaf-water potential (IPD) was determined once per week at the day prior to irrigation in all treatments. Measurements were carried on six fully expanded leaves from each treatment using a Scholander pressure chamber (Skye Instruments, Powys, UK). Concomitant measurements of maximum stomatal conductance (Cs) and photosynthetic rate $(\mathrm{Pn})$ were performed from 900 to1000 $\mathrm{h}$ at saturating light intensity (PAR $\left.\geq 1000 \mu \mathrm{mol} \mathrm{m}^{-2} \mathrm{~s}^{-1}\right)$ in nine leaves per treatment using an open gas exchange system (LC pro+ ADC BioScientific, UK). Gas exchange determinations were done in leaves from those plants that were prior used for predawn leaf

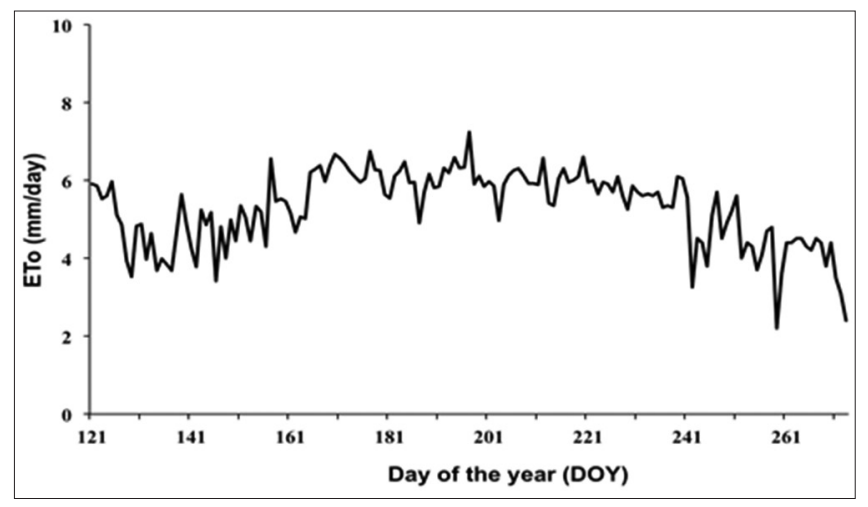

Fig 1. Changes in daily reference evapotranspiration $\left(E T_{0}\right)$ during the experimental period in the pomegranate orchard.

water potential measurements. Diurnal changes in gas exchange parameters were performed in all treatments, once per month, during the summer period.

Fruits quality evaluation was performed at harvest. Fruit diameter and weight were measured in 90 fruits per treatment using an electronic digital caliper. Fruits with cracking were collected separately and their number was expressed as percentage of all fruits. For juice determinations, pomegranates were peeled and the arils as well as peel were weighted separately. The arils were then homogenized using a blender, the juice weighted and the yield was expressed as percentage. Titratable acidity (TA) was determined by titration of fruit juice with $0.2 \mathrm{~N}$ sodium hydroxide $(\mathrm{NaOH})$ solution in presence of phenolphthalein indicator and expressed as citric acid percent (AOAC, 2000). Total soluble solids (TSS) were determined by a hand-held refractometer and data showed as Brix at $20^{\circ} \mathrm{C}$. Furthermore, the $\mathrm{pH}$ of fruit juice was measured using a calibrated digital $\mathrm{pH}$ meter and values were expressed in $\mathrm{pH}$ units.

\section{RESULTS AND DISCUSSION}

Different irrigation treatments resulted in significant changes in the plants physiological parameters. In particular, seasonal changes in stomatal conductance revealed lower values in both PRD treatments compared to the control (Fig. 2).

Since stomatal conductance is known to be dependent on plants hydrodynamic parameters, predawn water potential $\left(\Psi_{\mathrm{PD}}\right)$ values were expected to be significantly lower in PRD treatments in comparison to control plants. However, this was only evident in PRD2 treatments (Fig. 3) while in PRD1 treatment $\Psi_{\mathrm{PD}}$ values were higher than the control (the latter differences were significant in the two out of five and in the four out of five measurements in July and August respectively). 


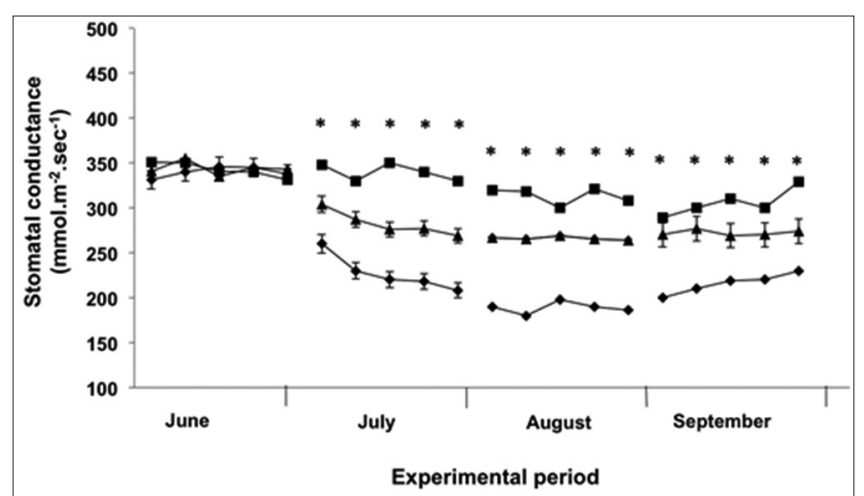

Fig 2. Seasonal changes in leaf stomatal conductance of Punica granatum L. Cv. Wonderful subjected to partial root drying treatments $(\boldsymbol{\nabla}=$ Control, $\boldsymbol{\Delta}=$ PRD 1 and $\boldsymbol{\nabla}=$ PRD 2). Each point represents the mean value + standard error of 9 measurements. Asterisks indicate significant differences between treatments $(P<0,05)$.

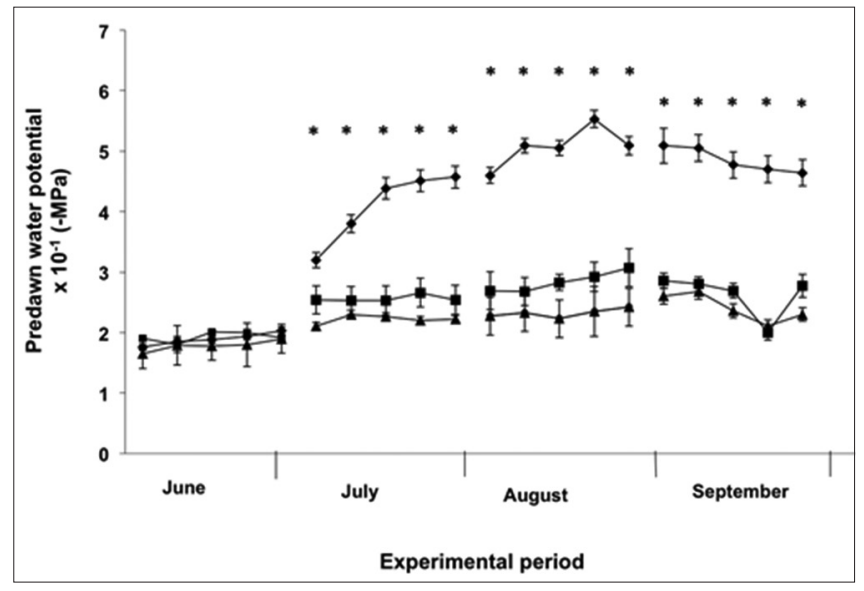

Fig 3. Seasonal changes in predawn water potential $\left(\Psi_{\mathrm{PD}}\right)$ of Punica granatum L. Cv. Wonderful subjected to partial root drying treatments ( $\mathbf{\square = C o n t r o l , ~} \boldsymbol{\Delta}=$ PRD 1 and $\boldsymbol{\nabla}$ = PRD 2). Each point represents the mean value \pm standard error of 6 measurements. Asterisks indicate significant differences between treatments $(P<0,05)$.

Lower stomatal conductance values in PRD1 despite the higher values of $\Psi P D$ provide evidences for involvement of chemical signals in stomatal regulation. Indeed, it is well known that in PRD methodology chemical signals being produced in the drying part of roots are moving to leaves through transpiration stream, affecting stomatal conductance (Stoll et al., 2000; Liu et al., 2006). In line with our findings, lower Cs values have been reported in PRD compared with control plants in orange (Hutton and Loveys, 2011) and olive trees (Wahbi et al., 2005). However, the fact that in our results Cs values were lower in PRD1 despite the higher values of leaf water potential suggest that this mechanism of root signal mediating stomatal responses seems to be preponderant in the absence or under mild drought conditions. On the contrary, under more intense drought condition (PRD2 treatment) stomatal conductance seems to progressivelly be also more dependent on plant water status.

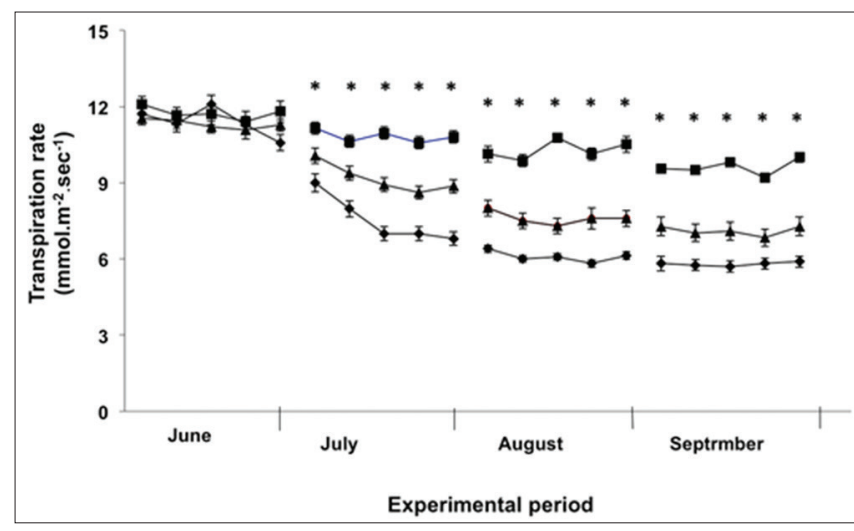

Fig 4. Seasonal changes in transpiration rate of Punica granatum L. cv. Wonderful subjected to partial root drying treatments $(\boldsymbol{\nabla}=$ Control, $\boldsymbol{\Delta}=$ PRD 1 and $\diamond=$ PRD 2). Each point represents the mean value \pm standard error of 9 measurements. Asterisks indicate significant differences between treatments $(P<0,05)$.

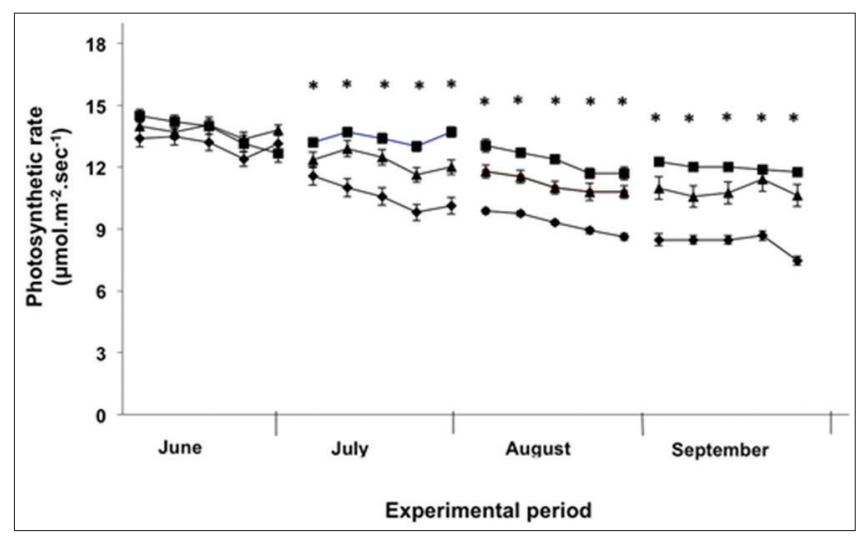

Fig 5. Seasonal changes in photosynthetic rate of Punica granatum L. Cv. Wonderful subjected to partial root drying treatments ( $\boldsymbol{\nabla}=$ Control, $\boldsymbol{\Delta}=$ PRD 1 and $\boldsymbol{\nabla}=$ PRD 2). Each point represents the mean value \pm standard error of 9 measurements. Asterisks indicate significant differences between treatments $(P<0,05)$.

Differences in stomatal conductance seemed to mostly affect transpiration rate. The latter was significantly lower in PRD treatments (Fig. 4) compared to control. In PRD1 treatments lower transpirational rate in addition to the existence of adequate soil water content resulted in the maintenance of almost constant values of leaf water potential in this treatment throughout the experimental period (Fig. 3). Furthermore, lower stomatal conductance seemed not to considerably affect photosynthetic rate in PRD1 treatment, which remained quite similar to those of the control treatment (Fig. 5). Diurnal values also indicated minor differences of photosynthetic rate between the PRD1 and control treatments but revealed significant differences between control and PRD2 (Fig. 6). Lower values of photosynthetic rate in PRD2 treatments are expected to affect quantity and quality of the products. Indeed, mean fruit weight was significantly lower in PRD 2 plants compared to the control (Table 1) while there were no significant differences in fruit quality parameters. The 
Table 1: Changes in pomegranate fruit quality parameters and juice production in response to different irrigation treatments

\begin{tabular}{|c|c|c|c|c|c|c|c|c|}
\hline Treatments & $\begin{array}{l}\text { Mean fruit } \\
\text { weight }(\mathrm{g})\end{array}$ & $\begin{array}{c}\text { Mean fruit } \\
\text { diameter }(\mathrm{mm})\end{array}$ & $\begin{array}{l}\text { Aril weight } \\
(\times 50)(\mathrm{g})\end{array}$ & $\begin{array}{c}\text { Juice } \\
\text { percentage }\end{array}$ & $\begin{array}{c}\text { Fruit } \\
\text { cracking (\%) }\end{array}$ & $\begin{array}{l}\text { Titratable } \\
\text { acidity (\%) }\end{array}$ & $\begin{array}{c}\text { Total soluble } \\
\text { solids (\%) }\end{array}$ & pH \\
\hline Control & $413,4^{a}$ & $99,5^{\mathrm{a}}$ & $16,1^{\mathrm{a}}$ & $29,3^{a}$ & $10,65^{a}$ & $22,3^{a}$ & $15,80^{a}$ & $3,23^{a}$ \\
\hline PRD 1 & $449,1^{a}$ & $101,2^{a}$ & $17,1^{\mathrm{a}}$ & $30,2^{a}$ & $8,31^{b}$ & $21,4^{\mathrm{a}}$ & $16,60^{b}$ & $3,27^{a}$ \\
\hline PRD 2 & $391,7^{b}$ & $90,1^{b}$ & $15,8^{a}$ & $27,1^{\mathrm{a}}$ & $11,34^{\mathrm{a}}$ & $23,4^{a}$ & $15,46^{a}$ & $3,18^{a}$ \\
\hline
\end{tabular}

Data represent average values \pm standard error $(n=90)$. Different letters in the same column indicate significant difference at $P<0,05$

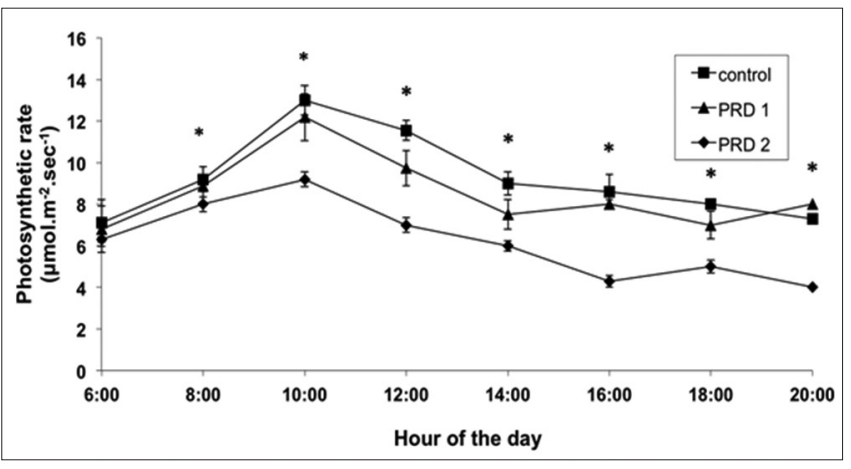

Fig 6. Diurnal changes in photosynthetic rate of Punica granatum L. cv. Wonderful subjected to partial root drying treatments. Each point represents the mean value \pm standard error of 9 measurements. Asterisks indicate significant differences between treatments $(\mathrm{P}<0,05)$.

lower fruit weight in this treatment might be attributed to the smaller size of the fruits as indicated by the lower fruit diameter. On the other hand, PRD1 fruits exhibit the highest values of fruit weight, diameter and total soluble solids concentration. A possible explanation could be based on the well-known negative effects of PRD strategy to lateral shoot growth, which in turn favors the accumulation of photosynthetic products in fruits (Beis and Patakas, 2010). Titratable acidity, $\mathrm{pH}$ as well as juice percentage were not affected by differences in irrigation methodology. This is consistent with the results reported by Mena et al. (2013) and Mellisho et al. (2012) who showed that water stress did not affect the basic quality parameters of the pomegranate juice. In this reports a slight but significant reduction in pomegranate quality parameters was found only under severe water stress (12\% of ET $)$.

Of greater importance was the significant decrease in fruit cracking observed in the PRD1 treatment (Table 1). Fruit cracking is considered as a major fruit disorder for pomegranate mainly associated with sudden changes in plant water status. It is believed that pomegranate is very sensitive to variation in soil moisture. When soil drought is followed by an increase in soil moisture content, the fruits pulp expands before the peel, causing the fruit cracking (Holland et al., 2009). The fact that water status in PRD1 plants remained relatively unchanged during the growing period (Fig. 3) provides evidences that such stability might be responsible for the low percentage of fruit cracking in this treatment.

\section{CONCLUSIONS}

A significant effect of PRD irrigation on plant physiology in pomegranate plants was revealed. As far as the fruit quality is concerned, data indicated a positive impact of PRD irrigation on reducing fruit cracking, provided that the amount of irrigation water applied could replace the evapotranspiration losses. However, more detailed analysis is needed, using irrigation amounts equal to different fractions of plants evapotranspiration losses as well as different varieties, in order to verify PRD impact on both pomegranate water productivity and fruit quality.

\section{Authors contributions}

All the authors of the paper contributed equally to the writing of the paper and were involved in the overall planing and supervision of the work.

\section{REFERENCES}

Allen, R. G., R. S. Pereira, D. Raes and M. Smith. 1998. Crop evapotranspiration - Guidelines for computing crop water requirements. FAO Irrigation and Drainage Paper No 56: 15-27, Rome, Italy.

Beis, A. and A. Patakas. 2010. Differences in stomatal responses and root:shoot signalling between two grapevine varieties subjected to drought. Funct. Plant Biol. 37: 139-146.

Beis, A. and A. Patakas. 2015. Differential physiological and biochemical responses to drought in grapevines subjected to partial root drying and deficit irrigation. Eur. J. Agron. 62: 90-97.

Holland, D., K. Hatib and I. Bar-Yàakov. 2009. Pomegranate: Botany, horticulture, breeding. Hortic. Rev. 35: 127-191.

Hutton, R. J. and B. R. Loveys. 2011. A partial root zone drying irrigation strategy for citrus effects on water use efficiency and fruit characteristics. Agric. Water Manage. 98: 1485-1496.

Intrigliolo, D. S., E. Nicolas, L. Bonet, P. Ferrer, J. J. Alarcón and J. Bartual. 2011. Water relations of field grown pomegranate trees (Punica granatum) under different drip irrigation regimes. Agric. Water Manage. 98(4): 691-696.

Intrigliolo, D. S., L. Bonet, P. A. Nortes, H. Puerto, E. Nicolas and J. Bartual. 2013. Pomegranate trees performance under sustained and regulated deficit irrigation. Irrig. Sci. 31(5): 959-970.

Kriedemann, P. E. and I. Goodwin. 2003. Regulated Deficit Irrigation and Partial Root- Zone Drying. An Overview of Principles and Applications, Irrigation Insights No. 4. Land and Water Australia, Canberra.

Laribi, A. L., L. Palou, D. S. Intrigliolo, P. A. Nortes, C. Rojas-Argudo, V. Taberner, J. Bartual and M. B. Pérez-Gago. 2013. Effect of sustained and regulated deficit irrigation on fruit quality of 
pomegranate cv. 'Mollar de Elche' at harvest and during cold storage. Agric. Water Manag. 125: 61-70.

Liu, F. L., C. R. Jensen and M. N. Andersen. 2005. A review of drought adaptation in crop plants: changes in vegetative and reproductive physiology induced by ABA - Based chemical signals. Aust. J. Agric. Res. 56: 1245-1252.

Mellisho, C. D., I. Egea, A. Galindo, P. Rodríguez, J. B. Rodríguez, W. Conejero, F. Romojaro and A. Torrecillas. 2012. Pomegranate (Punica granatum L.) fruit response to different deficit irrigation conditions. Agric. Water Manag. 114: 30-36.

Mena, P., A. Galindo, J. Collado-González, S. Ondoño, C. GarcíaViguera, F. Ferreres, A. Torrecillas and A. Gil-Izquierdo A. 2013. Sustained deficit irrigation affects the colour and phytochemical characteristics of pomegranate juice. J. Sci. Food Agric. 93(8): 1922-1927.

Prasad, R. N., G. J. Bankar and B. B. Vashishtha. 2003. Effect of drip irrigation on growth, yield and quality of pomegranate in arid region. Indian J. Hortic. 60: 140-142.

Rodrigues, M. L., T. P. Santos, A. P. Rodrigues, C. R. Souza, C. M.
Lopes, J. P. Maroco, J. S. Pereira and M. M. Chaves. 2008 Hydraulic and chemical signalling in the regulation of stomatal conductance and plant water use in field grapevines growing under deficit irrigation. Funct. Plant Biol. 35: 565-579.

Santos, T. P., C. M. Lopes, M. L. Rodrigues, C. R. Souza, J. P. Maroco, J. S. Pereira, J. R. Silva and M. M. Chaves. 2003. Partial rootzone drying: effects on growth and fruit quality of field-grown grapevines (Vitis vinifera). Funct. Plant Biol. 30: 663-667.

Smart, D. R., E. Carlisle, M. Goebel and B. A. Núñez. 2005. Transverse hydraulic redistribution by a grapevine. Plant Cell Environ. 28: 157-166.

Stoll, M., P. Dry, B. Loveys, D. Stewart and M. McCarthy. 2000. Partial root-zone drying. Effects on root distribution and commercial application of a new irrigation technique. Aust. N. Z. Wine Ind. J. 15: 74-77.

Wahbi, S., R. Wakrim, B. Aganchich, H. Tahi and R. Serraj. 2005. Effects of partial root zone drying (PRD) on adult olive tree (Olea europaea) in field conditions under arid climate. I. Physiological and agronomic responses. Agric. Ecosyst. Environ. 106: 289-301. 